\title{
An alternative Approach to Power Engineering education
}

Pedersen, Knud Ole Helgesen; Havemann (retired June, 2000), Henrik

Published in:

Proceedings of Power Engineering Society Summer meeting

Link to article, DOI:

10.1109/PESS.2000.866968

Publication date:

2000

Document Version

Publisher's PDF, also known as Version of record

Link back to DTU Orbit

Citation (APA):

Pedersen, K. O. H., \& Havemann (retired June, 2000), H. (2000). An alternative Approach to Power

Engineering: education. In Proceedings of Power Engineering Society Summer meeting (Vol. 4, pp. 2085-2090). IEEE. https://doi.org/10.1109/PESS.2000.866968

\section{General rights}

Copyright and moral rights for the publications made accessible in the public portal are retained by the authors and/or other copyright owners and it is a condition of accessing publications that users recognise and abide by the legal requirements associated with these rights.

- Users may download and print one copy of any publication from the public portal for the purpose of private study or research.

- You may not further distribute the material or use it for any profit-making activity or commercial gain

- You may freely distribute the URL identifying the publication in the public portal

If you believe that this document breaches copyright please contact us providing details, and we will remove access to the work immediately and investigate your claim 


\section{An Alternative Approach to Power Engineering.}

\author{
Knud Ole Helgesen Pedersen \\ Department of Electric Power Engineering \\ Technical University of Denmark \\ Build. 325, DK-2800 Lyngby \\ Denmark
}

\author{
Henrik Havemann \\ Department of Electric Power Engineering \\ Technical University of Denmark \\ Build. 325, DK-2800 Lyngby \\ Denmark
}

\begin{abstract}
In a drive to attract more students, three new courses have been introduced at the Department of Electric Power Engineering of the Technical University of Denmark. Among many students, Power Engineering has a reputation of being old-fashioned and static, whereas Information Technology is regarded as young and dynamic. Consequently, the new courses apply Information IT as a gateway to Power Engineering. The courses present the students with, 1) a meaningful, easy understandable Power Engineering problem, 2) a realistic set-up in the laboratory and 3) a microprocessor system used as a tool to solve the problem. The students work mainly with programming but as the course develops they gain preliminary insight into the field of Power Engineering and experience that it is a broad field exploiting various advanced disciplines. In addition, course timing is highly important. Students must be confronted at an early stage of their study before they make a decision to specialise.
\end{abstract}

Keywords: Power engineering education, Microprocessor applications, Information technology, Wind power generation, Protective relaying.

\section{INTRODUCTION}

The power-engineering field at the Technical University of Denmark (DTU) attracts too few students. Power engineering seems to have an image problem. It is regarded as a static field mainly associated with polluting power plants, unpopular transmission lines and heavy machinery which has been unchanged in design for years. For most students information technology looks much more challenging and dynamic and with an ecologically responsible image.

On the other hand, nobody denies the benefits of electric power and a reliable power supply is almost considered as a human right. In recent years, the power field has been fast inventory on the political agenda. More recently, it has become headline news due to both the coming free market and the increasing use of alternative non-polluting energy resources. In Denmark, a political decision has been made to extend considerably the electricity production from windmills, and in the near future huge offshore wind farms are planned.

Thus, students do not need to be convinced that power engineering is of importance to society but they do need to be convinced that it is a technologically interesting and advanced field. As modern power engineering becomes increasingly more IT-oriented, a way to attract student attention could be to highlight in relevant IT-applications in power engineering courses.

Fortunately, the nature of power engineering and the equipment available in a power laboratory makes it straightforward to formulate meaningful problems, with an immediate practical aspect that should appeal to most students. The problem should be structured so that its solution requires primarily the use of information technology. No prior detailed knowledge to power engineering should be invoked. Hence, the student can gain an insight into power engineering while mainly working with information technology. In that way the student can experience immediately that power engineering is a broad field involving various advanced disciplines.

This is the philosophy behind new courses initiated at the Department of Electric Power Engineering (ELTEK) at DTU.

\section{STRUCTURE OF STUDY AT DTU}

DTU offers students a 5-year research based Master's degree programme. The course is modular and students form their own combination of modules - with basic compulsory modules accounting for some $30 \%$. DTU has a two-semester academic year. Each semester is divided into a 14-week period followed by an examination period of $\sim 4$ weeks and after that a 3-week period during which students work full time on a specific subject.

During the first four semesters, students must enrol in one of eight preliminary programmes covering different areas among which Electrical Engineering and Energy Technology are closest related to power engineering. After these first two years, it is very much up to each student to plan his/her own curriculum.

Half way through the study students participate in a socalled mid-way project where a complex engineering problem is considered, often as an interdisciplinary problem. The students work in project groups and half of the time during the semester is allocated to the project. Each department at DTU offers mid-way projects giving each student an opportunity to select a project, which fits his/her special interests. 
After the mid-way project, students specialise by following courses in specific fields - such as power engineering. The last semester is devoted to a Master's thesis project.

If more students are to be guided into power engineering, initiatives that address first and second year's students must be undertaken. Looking at the study structure three possibilities appear:

\section{1) Preliminary program}

In the second semester of the preliminary program, students work on a minor project. ELTEK has defined such a project focused on windmills and on methods to connect windmills to the power grid.

During the 14-week period, students work part time on the project making introductory studies and planning a solution. In the succeeding 3-weeks period, they concentrate full time on the project and implement the solution on a model in the laboratory.

No prior knowledge to power techniques is required to sign up for this project, although an elementary background in electronics and programming is necessary.

\section{2) 3-week course}

ELTEK offers students a 3-week course in basic microprocessor applications. Recently the course emphasise has been renewed so that students now practise microprocessor programming by building a digital distance relay. This is a well-suited problem for microprocessor training, but at the same time introduces the students to the analysis of power system signals.

During the three weeks, students work full time in the department. This is an excellent opportunity to give students an insight into the department's activities and illustrate various aspects of power engineering.

3) Mid-way project

A proposal for a new mid-way project is under consideration. The idea is to monitor the power quality and the power production at an in-service, remote windmill. A distributed measurement system consisting of PC's linked together over the Internet is available for the project. Students have to establish a data flow from the raw measurements logged at the local PC at the windmill site to a database at DTU where parameters characterising the state of the power system are stored.

Common to the three courses is that information technology is used as a tool to solve realistic powerengineering problems. In that way, a door to power engineering may be opened for students who had not imagined this as their future career area. The courses are also of direct interest to students who already have decided on power engineering and who realise that a basic knowledge of microcomputer techniques is essential within the industry.

\section{III: PRELIMINARY PROJECT WINDMILL OPERATION}

\section{A. Objective}

Technically, the objective is to use a microprocessor system to control and monitor the operation of a windmill being exposed to different wind conditions. Educationally, the objective is to let new students - just with elementary qualifications in electronics and in programming - train their skills on a practical interdisciplinary engineering problem. Underway in the project, students are given a first insight into power engineering.

\section{B. Laboratory Set-up}

A model of a grid-connected windmill is build in the laboratory - see Fig. 1. The windmill itself is replaced by a 2 $\mathrm{kW}$ thyristor-driven DC-motor. The motor is torque controlled and the reference level of the torque is manually adjustable. The torque on a windmill is related to the wind speed and variations in the reference torque are used to represent changes in the wind conditions. Mechanical braking of the windmill is simulated simply by switching off the DCmotor.

The windmill drives a $2 \mathrm{~kW}$ induction generator. The terminals on the generator can be connected to the 3-phase $400 \mathrm{~V}$ power grid. A circuit-breaker is inserted to open or close the connection between generator and power grid. The model is prepared for measurements of: 1) the rotational speed of the motor shaft, 2) the currents in the 3 phases to the generator and 3) the active power produced/consumed by the generator.

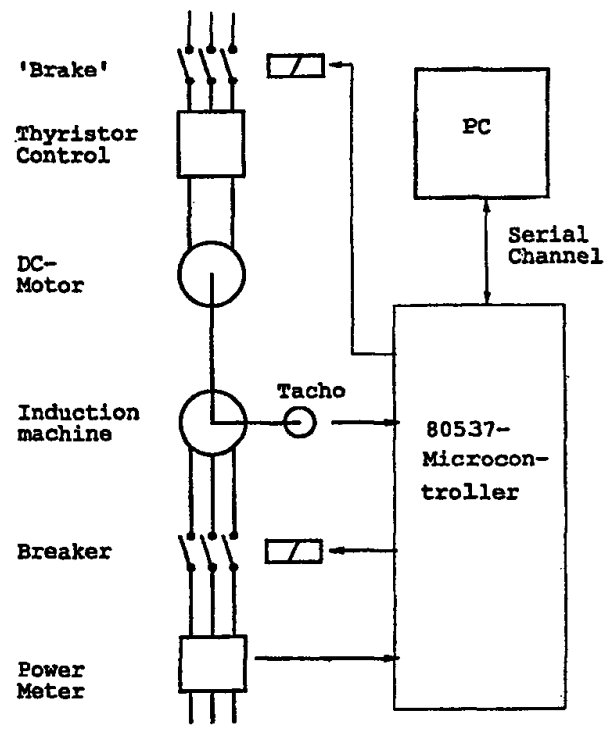

Fig. 1: Laboratory Model of Windmill

A dedicated microprocessor kit has been constructed to monitor and control the windmill model. The kit is based on an industrial 8-bit, $12 \mathrm{MHz} 80537$ - microcontroller which 
includes an on-chip 12 channel 8-bit AD-converter, several 8bit input/output ports and 2 serial communication channels.

The processor is well suited for this project since it is relatively simple and rather easy to overview by inexperienced programmers.

Two electronic relays are installed in the model - one to operate the circuit-breaker which connects or disconnects the generator from the power grid and the other to start or stop the DC-motor. The relays can be operated by the processor from two output bits, but a simple interface has to be built to adapt the signal from the output port to the relay.

The AD-converter measures signals in the range 0-5 V. Special signal-conditioning circuits have to be designed to fit the output signals from the measuring transducers into this 0 $5 \mathrm{~V}$ range, and to protect the converter against over/under voltage levels.

With this interface implemented, the windmill can be fully monitored and controlled from the 80537-kit. The microcontroller is programmed in C. Programming is carried out on a PC and all necessary program development tools are available.

The microcontroller is linked to a PC over a serial communication channel. The PC is used as the operator's interface to the windmill. The operator manoeuvres the windmill from the $\mathrm{PC}$ and windmill measurements are presented on the PC screen. The PC is programmed in Visual Basic as this is an easy-to-use Windows programming language.

\section{Course Schedule}

The first part of the project takes place in a 14-weeks period. The students form a general view of the problem and make preliminary studies encompassing both theory and method, which are required to solve the problem. This implies the activities listed below:

1) Identifying modes of operations of the windmill Intuitively, it can be foreseen that a windmill runs through the following states: a) No power production because the wind is too weak. b) Start of power production as the wind speed increases and accelerates the mill. c) Normal power production. d) Stop of production either because the wind abates or because wind speed is too high.

The problem is to find out when to shift between two states and to propose how to execute such a shift. Shifting criteria have to be worked out and the criteria must be based on the available process measurements. To set up realistic criteria some understanding of the interaction between the power grid and the windmill is necessary. This leads to an introduction of the 3-phase power system and of the principles and characteristics of the induction machine.
2) Designing signal-conditioning circuits

Operational amplifier circuits are designed to adapt the transducer signals to the microprocessor voltage level. $\mathrm{PC}$-based simulation tools are used to verify the design.

3) Preparing programming

To become acquainted with the C-language and with the 80537-microcontroller training in programming is initiated. Small exercises relevant for the project are presented and a feeling of the processor's potential when working in a $50 \mathrm{~Hz}$ real-time environment is attained. The serial communication is tried out and a PC-based Visual Basic user interface is planned.

The project continues in the 3-week period following the 14-week semester. During this phase the students implement and test their ideas in practise in the laboratory. The implementation is performed stepwise. First, some practical soldering work is necessary to build the signal conditioning circuits. Next, a real-time data acquisition system is programmed on the 80537-processor to measure the rotational speed, the phase currents and the power flow. After that, the criteria to shift between the different operational modes of the windmill are added and experiments are made to optimise the criteria. The performance is visualised on the $P C$, which receives the measured data over the serial channel. The power production - and its direction - is regularly updated on the PC-screen and an event recorder is programmed to capture the current surge that emerges when the generator is coupled to the grid. In that way, the importance of proper timing of the coupling can be studied.

At the end of the course, each group of maximum 3 students submits a report and makes an oral presentation of their work.

Underway in the course, visits are arranged to relevant industries so the students can see power engineering in practice.

\section{Experience Gained}

In the spring semester of ' 99 , the course was launched for the first time, with 14 students of Electrical Engineering participating. The students were very engaged in the project and even if their initial background knowledge was limited all the groups succeeded in controlling the windmill model. Obviously, some of the students concentrated more on programming and did not look too deeply into the power engineering aspects. However, the majority of students were inspired by experimenting with rather heavy machinery and by being able to understand and control such machinery.

The students' evaluation of the course was positive. All of them answered yes to the question "Would you recommend the course to your fellow students". Being at an early stage in 
their studies they could not give an assurance to specialise in power engineering, but their prejudice against power engineering was lessened considerably, which - in itself - is an achievement. The course is planned to run for the second time in the spring semester 2000.

A further challenge is that a group of students in Energy Technology has applied for the course. Educationally, this is an exciting prospect since these students primarily are interested in the social aspects of energy production and energy planning and at this stage of their study have very limited experience in programming and electronics.

\section{IV: 3-WEEK COURSE}

PROGRAMMING A DIGITAL DISTANCE RELAY.

\section{A. Objective}

Primarily, the course is meant to train $2^{\text {nd }}$ or $3^{\text {td }}$ year's students in basic microprocessor techniques by solving a practical real-time task. The goal is achieved by programming a digital distance relay and by proving its performance on a laboratory model of a transmission line. This is a task which squeezes the processor to its utmost limit due to the real-time requirements set by working on $50 \mathrm{~Hz}$ signals in the power system. Consequently, the students experience that microprocessors are part of the power engineering world and that power engineering utilises advanced signal analysis methods which can challenge any microprocessor.

\section{B. Laboratory Set-up}

A microprocessor board like the one used in the preliminary project is available in this course. It is based on the 80537-microcontroller, but extra units have been added such as a LCD-display, a keyboard and 12-bits ADC and DAC converters - see Fig. 2. The board makes up a generic process computer, which can monitor and control a real-time task limited only by the performance of the 80537microprocessor. There is no software included at all so the board has to be programmed from scratch. Program development is carried out on a PC, from where the executable code can be downloaded into a RAM-memory of the 80537-system over a serial channel.

The 80537-microcontroller is part of the well known 8051-family. This family of processors has been on the market for several years but is still intensively used in industrial applications. Since it is relatively simple processor; the students can overview what is going on internally. A speciality for the 80537 is that it contains an on-chip mathematical unit. This enables the 8-bits processor to perform fast, high precision calculations. This is a necessity when $50 \mathrm{~Hz}$ power signals have to be analysed in real-time.

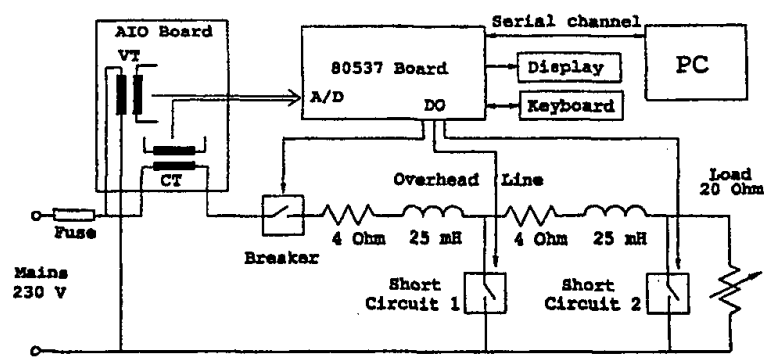

Fig. 2: Laboratory Model of Distance Relay Protected Power Line

A model of a transmission line has been established in the laboratory so the distance relay can be tested in realistic power engineering surroundings - see Fig. 2. It is a singlephase model build of two sections of resistances and inductances connected in series - with each section representing a length of the transmission line. The line supplies a variable resistive load. Short-circuits can be forced at the output of each section. These simulate earth faults at different points along the line. The model is fed from the $230 \mathrm{~V}$ mains. In case of a fatal fault, the current can be as high as $70 \mathrm{~A}$. Such a high current will rupture the main fuse after a short while. A successful distance relay avoids this by immediately cutting-off the line from the main supply by opening a breaker. At the same time, the distance relay indicates the position of the fault.

Two measuring transformers are installed to interface the voltage and the current of the power signal to the microprocessor. The breaker and the short-circuits can be activated from three output bits of the microprocessor via electronic relays.

\section{Course Schedule}

First of all, a basic input/output system - a so-called BIOS - is programmed so the microprocessor can output data to the LCD-display, take input from the keyboard and handle the ADC- and DAC-converters. A simple, interrupt driven real-time core is made to keep track of a real-time clock and to manage the timing of the measurements of voltage and current of the power signal. These features are combined to build a simple, RMS measuring instrument. This is not a very demanding task for the processor so programming can be made solely in the C-language. Pedagogically this intermediate goal is important because the students see at an early stage their efforts rewarded in a practical application before the more demanding part of the course commences.

Next, signal analysis algorithms are considered. The distance relay works on algorithms, which estimate the impedance of a network from equally spaced measurements of voltage and current fed to the network. The algorithms are taken from the literature - see [1]. A MATLAB-simulation is prepared so the students can study how the algorithms react when used on the laboratory model. In this manner, the 
students gain an insight into the dynamics of the algorithms and can observe how the estimation is influenced by the sampling rate, by disturbances in the power signal and by the resolution of the ADC-converter. Criteria for a reliable detection of a short-circuit fault and for indication of its position are proposed and verified.

Following this background experience, programming of the algorithms starts. Even if the algorithms look rather elementary, it is a laborious task for an 8-bit processor to perform such calculations with sufficient accuracy and within the time span determined by the sampling rate. Optimised ASM-programming is compulsory to fulfil these requirements. The relay is implemented and tested when connected to the laboratory model. Initially, a test under safe conditions is made by varying the load and noting if the relay derives the correct impedance. If the test is passed, then a short-circuit is provoked and it will immediately be found out whether the relay works satisfactory or not - a fuse survives or ruptures.

Finally, a modem connection to the relay is programmed so the relay can be supervised from a remote $\mathrm{PC}$. This feature is meant to challenge those students who in advance are experienced microprocessor programmers.

\section{Experience Gained}

During the last year and a half, approximately 50 students have attended the course. Practically all students enrolled because they wished to work with microprocessors and not because of the power engineering content. In spite of this, the students have been well motivated and have applied themselves diligently to solve the problem, which they found interesting and relevant. They had not expected this sort of work to arise in power engineering. Thus, a positive start towards convincing students that power engineering is the proper choice for specialisation has been achieved.

Even if $2^{\text {nd }}$ years students are the primary target group for the course, also students further ahead in their studies have participated. Several of these have continued in the department and have written their Master thesis, but in topics which are not considered as 'real' power engineering. They have designed $\mathrm{PC}$-based information systems used in research projects in the department inside Demand Site Management, development of new measuring equipment etc. This opens the question "Is the definition of power engineering too narrow and should it be broadened? ". With the introduction of the free market, electricity companies must seek new business areas, and thus new recruits to the industry must possess greater diversity. Therefore, a broadening of the content of the power-engineering curriculum along the avenues reported seems imperative.

\section{V: MID-WAY PRCJECT \\ MONITORING POWER QUALITY OF A REMOTE WINDMILL.}

At present, this new mid-way project is just a proposal and has not yet been launched. The idea originates from two windmill research projects ELTEK has been involved in during the past few years. Both projects look into the application of modern power electronic equipment to improve the connection between a wind farm and the power grid. The effect of the power electronics is demonstrated on full-scale installations. In one project two 4 Mvar ASVCs Advanced Static Var Compensator - have been build to supply the reactive power consumed by a $25 \mathrm{MW}$ windmill farm. In the other project, the new HVDC-light technology is used to transport energy ashore to the power grid from an offshore wind farm via a DC-line. ELTEK's part of the projects is to document the performance of the systems. For that purpose, a PC-based, distributed measurement system has been developed.

A PC located at the wind farm site acquires measurements and derives - in real-time - parameters characterising the power quality and the power production. The parameters are stored in data files, which are transmitted to ELTEK over an ISDN-channel. At ELTEK the data are organised in an SQLdatabase. These can easily be retrieved for detailed analyses. A special WEB-server is set up that allows the other partners in the project to access the database over the Internet. An overview of the configuration is shown in Fig. 3.

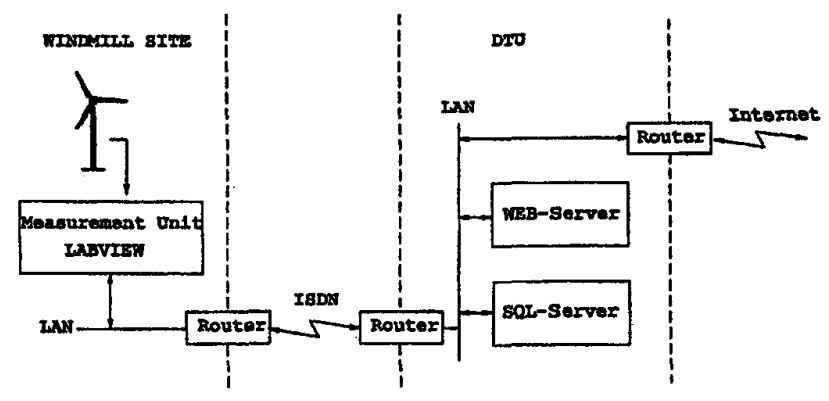

Fig. 3: Distributed PC-based Measuring System

A similar distributed PC-based system will be available in the mid-way project. The students have to program the system using standard PC-software tools. The following activities are foreseen:

1) Acquisition of measurements and calculation of power quality parameters by the $\mathrm{PC}$ at the windmill. The program package LABVIEW from National Instruments is used.

2) Establishing an FTP-connection between the PC at the windmill and a PC at ELTEK via an ISDN-link.

3) Designing an SQL-database to hold the windmill data. 
4) Retrieving specific data from the database in a form so these fit into EXCEL or MATLAB.

5) Publishing windmill data on a WEB-page.

Once more, it is a highly software oriented project and different programming techniques must be mastered to implement the system. However, before the programming phase can commence, students must specify the measurements to be taken and the parameters to be derived. This requires some power engineering knowledge of a windmill, its mode of operation and its interaction with the power grid. Furthermore, the concept of power quality must be understood.

An important motivation factor for the students is that measurements are taken from a fully operational commercial $2 \mathrm{MW}$ windmill.

\section{CONCLUSION}

In one respect, the strategy of attracting students to power engineering through information technology has been a success. A satisfactory number of students have enrolled for the new courses. Even if most students attended because of the microprocessor applications then they found the power engineering aspects surprisingly interesting and inspiring. This proves that power engineering problems can be made appealing to students if the proper pedagogical approach is taken. Whether this is sufficient for students to specialise in power engineering at a later stage of their studies will be seen in the years to come.

\section{REFERENCES}

[1] H.Kudo, H.Sasaki, K.Seo, M.Takahashi, K.Yoshida, T.Maeda, "Implementation of Digital Distance Realy using an Interpolated Integral Solution of a Differential Equation", IEEE Trans. Power Delivery, Vol 3, No. 4, October 1988

\section{BIOGRAPHIES}

Knud Ole Helgesen Pedersen was born in Copenhagen, Demark in 1943. He received his M.Sc. in Electrical Engineering in 1967 and his Ph.D. in Automatic Control in 1970, both from the Technical University of Denmark. From 1970 to 1973 he worked at CERN, Geneva and from 1973 to 1985 in Danish Industry as a Research Engineer, in all the years mainly occupied with Digital Process Control. Since then, he has been an Associate Professor at the Technical University of Denmark with his main interest in Microcomputer Applications in the Power System.

Henrlk Havemann was born in Copenhagen, Denmark, on October 10, 1937. He graduated with a master degree in electrical engineering in 1962. Since 1965 he has emplyed on the Technical University. From 1996 in Department of Electrical Power Engineering and he is now working with HVDC. 